\title{
RESENHA DO LIVRO “LEGADOS DE MEGAEVENTOS ESPORTIVOS"
}

\author{
REVIEW OF THE BOOK "LEGADOS DE MEGAEVENTOS ESPORTIVOS"
}

RESEÑA DEL LIBRO "LEGADOS DE MEGAEVENTOS DEPORTIVOS"

\author{
Andressa Peloi Bernabé*, Vitor Hugo Marani*, \\ Silvia Bandeira da Silva Lima*, Thaís Andréa Puzzi de Andrade*, \\ Fernando Augusto Starepravo*
}

\author{
Palavras-chave \\ Megaeventos \\ esportivos. \\ Legados. \\ Brasil
}

\begin{abstract}
Resumo: A presente resenha tem o intuito de realizar uma análise do livro "Legados de megaeventos esportivos", organizado por Nelson Carvalho Marcellino. A obra apresenta discussões em relação aos legados de megaeventos esportivos advindas de diversas áreas, voltando-se ao contexto brasileiro. A preocupação, no decorrer dos quatorze capítulos que compõem a obra, recai em demonstrar constatações que vão ao encontro das situações vivenciadas em meio ao período de preparações para os próximos megaeventos esportivos no país. Tal preocupação funda-se em reflexões que contribuem com o debate acerca das contradições, limitações e avanços que envolvem os megaeventos esportivos em nosso país.
\end{abstract}

Abstract: This is a review of the book "Legados de megaeventos esportivos" (The legacies of mega sporting events), edited by Nelson Carvalho Marcellino. The work presents discussions regarding legacies of mega sporting events from several areas, focusing on the Brazilian context. The fourteen chapters are concerned with showing findings about the situations experienced during the period of preparation for the coming mega sporting events in Brazil. Such concern is based on reflections that contribute to the debate about contradictions, limitations and advances involving mega sporting events in our country.

Resumen: Esta reseña tiene como objetivo realizar un análisis del libro "Legados de megaeventos deportivos" organizada por Nelson Carvalho Marcellino. El trabajo presenta las discusiones sobre legados de megaeventos deportivos provenientes de varias zonas, con foco en el contexto brasileño. La preocupación, a lo largo de los catorce capítulos que componen la obra, es demostrar constataciones que confirman situaciones vividas durante el período de preparación para los próximos megaeventos deportivos en el país. Esta preocupación se basa en reflexiones que contribuyen al debate sobre las contradicciones, limitaciones y avances relacionados con megaeventos deportivos en nuestro país.
*Universidade Estadual de Maringá, Maringá, PR, Brasil.

E-mail: andressa.bernabe@ hotmail.com

Recebido em: 27-05-2014

Aprovado em: 10-10-2014

(c) (1) (8) Licence 
Em virtude das realizações, em 2014 e 2016, no Brasil, da Copa do Mundo de Futebol Masculino FIFA (Copa do Mundo FIFA 2014) e dos Jogos Olímpicos e Paralímpicos (JO/PO), discussões a respeito de legados de megaeventos esportivos tomam corpo (RUBIO, 2007; DACOSTA et al., 2008; MASCARENHAS; BIENENSTEIN; SÁNCHEZ, 2011; EDIÇÃO N. $32-$ 33 - REVISTA MOTRIVIVÊNCIA, 2009; EDIÇÃO N. 41 - REVISTA MOTRIVIVÊNCIA, 2013; EDIÇÃO N. 89 - REVISTA EM ABERTO, 2013). É nesse contexto que a obra "Legados de megaeventos esportivos", organizada por Nelson Carvalho Marcellino, é lançada em 2013 com o objetivo de fornecer elementos para a compreensão das possíveis relações entre as mais diversas áreas do conhecimento com os megaeventos esportivos.

Por apresentar um mosaico de múltiplas abordagens, além do trato de temáticas como infraestrutura; formação e atuação de profissionais das áreas de esporte e lazer no contexto da organização dos megaeventos esportivos; controle social; políticas públicas; economia; dentre outras, a obra conduziu a estruturação da resenha, num primeiro momento, à síntese de cada um dos quatorze capítulos, e posteriormente à apresentação da percepção geral da presente obra, abordando suas contribuições, limitações e implicações para o campo de conhecimento da Educação Física.

No primeiro capítulo do livro, "Legados de megaeventos: abordagem geral", Nelson Carvalho Marcellino caracteriza os megaeventos esportivos e seus legados, bem como afirma que, dentre as definições presentes na literatura, encontram-se pontos comuns, como a concentração temporal e espacial, a consideração de sua abrangência e a necessidade de planejamento. Aspectos como grandiosidade, mercado-alvo definido, extensão pela mídia, necessidade de instalações, impactos sociais e econômicos também são considerados na definição de megaeventos. Ao discutir legado, o autor afirma que fatos como os investimentos advindos de recurso público e a transparência em relação aos gastos com a Copa 2014, patrocinada por organizações não governamentais (ONGs) e pela imprensa, podem comprometer os legados dos megaeventos em nosso país. Por fim, aponta a necessidade de considerar os megaeventos como parte da política pública de esporte e lazer para se atingir tais benefícios.

O objetivo do segundo capítulo, de Rejane Penna Rodrigues, volta-se à compreensão das relações construídas para a consolidação dos legados dos JO/PO em políticas públicas de esporte e lazer do Brasil. A autora entende legado como narrativa, no sentido de articular trajetórias passadas, presentes e futuras de uma cidade em processo de desenvolvimento, sendo esse o desafio que o Brasil enfrenta no momento. Além disso, conclui que os impactos e legados vêm sendo ampliados não só para o esporte e lazer, mas para políticas públicas em geral, a partir de uma governança interfederativa que busca superar riscos e desafios, possibilitando que o Brasil mostre ao mundo sua competência a partir da construção de um legado inestimável para a sociedade.

No terceiro capítulo da obra, Cláudia Regina Bonalume busca refletir acerca da significação dos megaeventos esportivos para o país em relação ao controle social em políticas públicas de esporte e lazer. Segundo a autora, pode-se constatar que a preocupação com o controle social está presente nas áreas de esporte e lazer, porém não há uma relação direta com a realização dos megaeventos esportivos, uma vez que o contexto brasileiro não se demonstra favorável à participação e ao controle social. Para a autora, a criação de organismos de controle em virtude dos megaeventos esportivos já pode ser considerada um legado, mas há 
muito a se avançar no sentido da participação no acompanhamento, fiscalização e interferência na aplicação dos recursos públicos.

Em "Legados dos megaeventos esportivos na pesquisa", Cláudia Regina Cavaglieri afirma que o Brasil é uma das mais promissoras nações do mundo tendo destaque na mídia mundial, o que contribuiu para a escolha do país como sede dos próximos megaeventos esportivos. Em relação à produção do conhecimento, a autora destaca que, apesar de uma vasta literatura internacional sobre os legados de megaeventos, há poucos estudos a respeito de seu impacto sobre o desenvolvimento científico de uma nação, e assim, afirma que os megaeventos esportivos devem contribuir para a formação de recursos humanos e a qualificação da produção do conhecimento nacional.

O quinto capítulo busca explorar o legado sociocultural proporcionado pelos megaeventos esportivos, com base no papel desempenhado pelos atletas e pelas instituições organizadoras. Desenvolvido por Raoni P. T. Machado e Katia Rubio, esse capítulo aponta que existe uma preocupação por parte do Comitê Olímpico Internacional (COI) e da FIFA em expor o valor dos atletas para a sociedade, uma vez que o esporte tem ocupado lugar de destaque, tornando-se importante ferramenta na propagação de ideais educativos. Porém, para tornar o espetáculo atrativo, o esporte acaba se tornando refém dos meios de comunicação e patrocinadores que não se preocupam com a educação e a moral a partir das condutas e ações dos atletas e dirigentes. Para os autores, os atletas profissionais e os meios de comunicação de massa precisam estar conscientes de seus papeis, para facilitar a ação de professores que usarão seus exemplos em diversas esferas educacionais.

Com o objetivo de destacar, do ponto de vista econômico, os resultados dos esforços para a elaboração, organização e execução dos megaeventos esportivos no Brasil, o sexto capítulo, de Roberto Brito de Carvalho, aponta legados positivos, dentre os quais: mobilidade urbana, infraestrutura esportiva, visibilidade internacional, desenvolvimento econômico, profissionalização do esporte, entre outros. Também aponta aspectos negativos, tais como: projetos de mobilidade urbana que não sairão do papel, infraestruturas esportivas com investimentos vultosos e a ociosidade pós-eventos, trabalhadores que ficam desempregados após o término das obras, possibilidade de endividamento público, uma vez que praticamente 95\% dos recursos utilizados advêm de setores públicos, a falta de transparência na gestão pública, entre outros. $O$ autor conclui que quase todos os investimentos feitos objetivam atender aos megaeventos, quando o ideal seria pensar em investimentos que atendessem aos anseios da população, convergindo em necessidades dos megaeventos.

Ricardo Ricci Uvinha busca refletir, no sétimo capítulo, sobre os investimentos realizados nos megaeventos esportivos no Brasil e sobre seu possível impacto nos segmentos do turismo e da hotelaria. 0 autor enfatiza investimentos em informação e orientação de turistas, acessibilidade e comunicação para portadores de deficiência, na oferta de serviços e acomodações de qualidade, e promoção dos destinos turísticos brasileiros. Em relação à hotelaria, aponta que foram lançados planos de financiamentos para a rede hoteleira pelo Banco Nacional de Desenvolvimento Econômico e Social (BNDES), bem como um programa de qualificação profissional pelo Governo Federal. $\mathrm{O}$ autor afirma a necessidade de se reconhecer a relevância dos programas que foram estabelecidos e o enorme potencial em legados de megaeventos esportivos. 
O oitavo capítulo, "Megaeventos: perspectivas para o lazer", de Nelson Carvalho Marcellino, analisa os megaeventos esportivos como fenômeno do lazer. Tal relação constrói-se a partir do rompimento com a visão funcionalista, compreendendo os megaeventos esportivos numa perspectiva educacional e cultural estabelecida a partir das relações com os valores olímpicos. A partir daí, reflexões são postas para se pensar uma nova pedagogia, baseada em perspectivas de mudança social e desenvolvimento de políticas públicas setoriais com participação popular, o que poderia despertar a criação de vivências da cultura esportiva ao preparar um espectador crítico e criativo.

José Roberto Bernasconi, autor do nono capítulo, "Legados para a infraestrutura", trata da relação entre os megaeventos esportivos e os investimentos em infraestrutura no Brasil. A reflexão proposta pelo autor remete à ideia de que os megaeventos aceleram os investimentos nesse setor e modificam a paisagem das cidades. Entretanto, como alerta Bernasconi, essas transformações exigem análises cautelosas, uma vez que são marcadas pela ausência de planejamento e de projetos que atendam às demandas sociais do país, o que pode refletir na inutilização e concessão das construções públicas à iniciativa privada, como observado em outras cidades que sediaram megaeventos esportivos, a exemplo de Atenas, Sidney e Londres.

Mirlei de Chaar Bahia, no capítulo "Legados socioambientais", focaliza os prováveis legados socioambientais relacionados aos megaeventos esportivos no Brasil. Para tanto, a autora discute a distância entre a legislação que garante o direito aos aspectos socioambientais brasileiros e a aplicação dessas leis junto ao planejamento urbano. A discussão ganha escopo a partir da crítica à remoção de moradores para a realização das obras voltadas aos espetáculos esportivos, o que evidencia a falta de diálogo entre as esferas legislativa e executiva. Por outro lado, a temática é tratada de forma benéfica para a revitalização social, cultural e ambiental das cidades, o que traduz possíveis legados positivos ao país.

No décimo primeiro capítulo, os autores Edmar Antonio Stoppa e Hélder Ferreira Isayama abordam a formação e a atuação de profissionais das áreas de esporte e lazer no contexto da organização dos megaeventos em nosso país. 0 exemplo de ações marcadas pela terceirização profissional e a falta de valorização dos profissionais ligados a esse campo de atuação elucida a desobrigação da administração pública, o que abre espaço para se pensar a necessidade do debate acerca da formação e atuação em esporte e lazer. Para tanto, os autores ressaltam a defesa da prática reflexiva, a participação crítica, e a formação contínua estimulada, principalmente, pelas universidades, o que possibilitaria a ampliação do conhecimento sobre esporte e lazer por meio do debate crítico relacionado aos megaeventos esportivos nos cursos de formação.

Simone Rechia e Emília Amélia Pinto Costa da Silva, responsáveis pelo décimo segundo capítulo, apresentam uma reflexão acerca dos possíveis legados sociais vinculados aos espaços e equipamentos de lazer e esporte que serão construídos e revitalizados para sediar megaeventos esportivos no Brasil. Nessa lógica, as autoras remetem à ideia de que as obras construídas para atender aos megaeventos esportivos podem não proporcionar espaços profícuos à população. Tal fato evidencia a necessidade de valores e significados a serem agregadas às futuras construções, o que aparece como possível saída para a criação de legados intangíveis junto à população.

O décimo terceiro capítulo, de Cinthia Lopes da Silva, apresenta considerações sobre os legados de megaeventos esportivos para a Educação Física Escolar, destacando aspectos 
negativos e positivos que podem refletir na disciplina. Dentre os aspectos negativos, a autora destaca o enfoque que pode ser dado aos megaeventos esportivos sem levar em consideração a realidade e a compreensão inicial dos alunos acerca desse tema, o que, todavia, pode ser minimizado por meio da inclusão dos aspectos positivos no planejamento da escola. Silva afirma que as aulas de Educação Física podem possibilitar aos alunos a produção de novos conhecimentos, o que ressalta a importância do debate, da reflexão e da ressignificação das práticas corporais em geral, dentre elas, 0 esporte.

O último capítulo, "Jogos paraolímpicos de 2016: um mundo de possibilidades", de Eline T. R. Porto e Eduardo de Paula Azzini, apresenta o trato reflexivo junto à Paralimpíada. A defesa do esporte paralímpico e os legados recorrentes do fenômeno justificam-se pela exibição de corpos desiguais que se encontram em movimento, o que gera alívio das indagações negativas rumo a ideias positivas em relação às pessoas com deficiência. A conclusão dos autores diz respeito à divulgação do esporte adaptado mundial e abertura de campo profissional fértil, o que auxiliará na quebra de paradigmas e preconceitos construídos no imaginário social da população em geral.

A partir da apresentação dos capítulos, pode-se constatar que a organização da obra finda seu objetivo de apreensão dos megaeventos esportivos a partir de diversas áreas do conhecimento, sobretudo quando pensada a maneira pela qual as informações recorrentes de cada capítulo são trazidas ao leitor. Tais informações, em sua maioria, são edificadas a partir de dados recursivos de pesquisas, leis e documentos, o que demonstra a preocupação em alcançar constatações por meio de subsídios que vão ao encontro de situações vivenciadas em meio ao período de preparações para os próximos megaeventos esportivos no país. Daí pensar em reflexões que contribuam com 0 debate acerca das contradições que cerceiam 0 período de preparação para a realização dos megaeventos esportivos, sobretudo, por meio da fuga de análises construídas em meio à opinião própria ou favorecimentos pessoais.

De fato, é preciso reconhecer que o trato junto à temática avança quando pensado em meio a outros escritos lançados anteriormente, que apresentavam, em alguns casos, informações frágeis que sofriam, principalmente, de carências metodológicas e conceituais, 0 que evidenciava a necessidade de reflexão intensa sobre o assunto. Todavia, atenta-se que tais obras constituem-se a partir do processo de estudo sobre discussões recém-instauradas no país, construídas notadamente a partir da escolha do Brasil enquanto país sede para a realização dos megaeventos esportivos. Portanto, apontavam para a busca de análises acerca dos megaeventos esportivos, especialmente, por meio de pesquisas que buscassem traçar panoramas para o Brasil, baseadas em experiências anteriores em outros países que haviam vivenciado tais experiências.

O convite de pesquisadores de diversas áreas do conhecimento apresenta-se como peça fundamental da obra aqui referenciada, bem como ressalta sua importância no cenário nacional, uma vez que os pesquisadores discorrem acerca de seus focos investigativos a partir de uma problemática comum, qual seja, o megaevento esportivo. Tal dinâmica merece destaque, mas apresenta fragilidades, principalmente em capítulos que traçam linhas superficiais em relação ao esforço reflexivo na interlocução entre os temas. Lacunas são constatadas na tentativa de ligação entre o assunto discutido em cada capítulo e a temática central da obra percebida somente no início e retomada apenas no desfecho analítico - carecendo de entrelace dessas informações, o que é esperado quando novos assuntos são incorporados a assuntos 
antigos. Essa limitação pode ser entendida, ainda, pelo viés da novidade em que 0 assunto se apresenta em meio às discussões acadêmicas, principalmente quando pensado em suas múltiplas facetas, o que assinala a potencialidade transdisciplinar do fenômeno, fundamental à obra durante todo o tempo.

Um dos destaques da obra diz respeito à maneira pela qual os autores tecem suas considerações acerca dos assuntos apresentados, independente da arbitrariedade dos fatos, conduzidos a partir dos referenciais utilizados por cada qual. Os legados apresentados aparecem cautelosamente junto aos textos, o que evidencia a preocupação em lançar mão de possibilidades e não predições unívocas. Assim, abre-se espaço para reconhecer a obra como campo fértil para leitores que não tenham estabelecido contato próximo à temática, possibilitando diversos olhares sobre diversos aspectos relacionados aos megaeventos esportivos. Daí a indicação do livro não só para a área da Educação Física, mas para todo campo de conhecimento que objetiva tecer discussões sobre a temática a fim de projetar, planejar, discorrer e lançar críticas de modo a alicerçar o desenvolvimento de legados dos megaeventos esportivos no Brasil.

\section{REFERÊNCIAS}

DACOSTA, L. et al. Legados de Megaeventos Esportivos. Brasília: Ministério do Esporte, 2008.

MARCELLINO, N. C. (Org.) Legados de megaeventos esportivos. Campinas: Papirus, 1ed, V.1, 2013.

MASCARENHAS, G.; BIENENSTEIN, G.; SÁNCHEZ, F. (Orgs.) 0 jogo continua: megaeventos esportivos e cidades. Rio de Janeiro: FAPERJ; EDUERJ, 2011.

REVISTA EM ABERTO, Brasília, v. 26, n. 89, jan./jun. 2013.

REVISTA MOTRIVIVÊNCIA. Dossiê 2007-2016 - A década dos megaeventos Esportivos no Brasil. n. 32-33, Florianópolis: UFSC, 2009.

REVISTA MOTRIVIVÊNCIA. Manifestações populares, cidadania e megaeventos esportivos. $n$. 41, Florianópolis: UFSC, dezembro de 2013.

RUBIO, K. (Org). Megaeventos esportivos, legados e responsabilidade social. São Paulo: Casa do Psicólogo, 2007 